\title{
Resilience Quantification and Its Application to a Residential Building Subject to Hurricane Winds
}

\author{
Berna Eren Tokgoz and Adrian V. Gheorghe* \\ Department of Engineering Management and Systems Engineering, Old Dominion University, Norfolk, VA 23529, USA
}

\begin{abstract}
In order to overcome negative consequences of a disaster, buildings and infrastructures need to be resilient. After a disaster occurs, they must get back to their normal operations as quickly as possible. Buildings and infrastructures should incorporate both pre-event (preparedness and mitigation) and post-event (response and recovery) resilience activities to minimize negative effects of a disaster. Quantitative approaches for measuring resilience for buildings and infrastructures need to be developed. A proposed methodology for quantification of resilience of a given building type based on different hurricane categories is presented. The formulation for the resilience quantification is based on a model embedding several distinct parameters (for example, structural loss ratios, conditional probabilities of exceeding for damage states, estimated and actual recovery times, wind speed probability). The proposed resilience formulation is applied to a residential building type selected from HAZUS.' Numerical results of resilience for the selected residential building type against Category 1, 2, and 3 hurricanes are presented in a dashboard representation. Resilience performance indicators between different types of buildings, which are identical except for their roof types, have been evaluated in order to present applicability of the proposed methodology.
\end{abstract}

Keywords building resilience, HAZUS, hurricanes, probabilistic resilience

\section{Introduction}

Wind related natural hazards, such as hurricanes, tornadoes, and thunderstorms can have great negative economic and social effects on individuals and society. Natural disasters are unpredictable and unavoidable. It is also impossible to determine and address all possible vulnerabilities and protect individuals, communities, and society against these disasters. The concept of resilience has gained much attention in disaster management, especially after the man-made disaster of the 9/11, 2001 attack, and the 2005 natural disaster of Hurricane Katrina. Even though resilience has been considered a buzzword for many years, recent academic studies and

\footnotetext{
* Corresponding author. E-mail: AGheorgh@odu.edu
}

governmental reports prove that resilience is an essential part of establishing a national security policy platform (Carlson et al. 2012).

Policy makers need a holistic approach to resilience to address the necessary actions and to avoid loss of lives as well as economic and social crises. As an evolving concept, resilience has been associated with the area of emergency management. It is believed that the resilience perspective can improve preparation, response, recovery, and mitigation efforts against risks in emergency management.

It is difficult to determine which actions are helpful in reducing adverse consequences of natural disasters. Resources must be used efficiently. Actions are taken by decision makers to apply necessary resilience strategies against disasters. There is a need for quantification of resilience to evaluate and compare effectiveness of preparation and mitigation strategies. There is ample information about specific mitigation actions, policies, and plans needed to reduce direct or indirect losses from extreme disasters. However, there is not much information about procedures on how to quantify the outcomes of these actions, policies, and plans as a function of recovery time, an important component of resilience (Cimellaro 2008a).

The objective of this article is to develop a methodology for resilience quantification of various buildings exposed to hurricanes. This work will be helpful in comparing different preparation and mitigation actions to improve, for instance, the resilience of communities. Resilience cannot be established at the national level without achieving it first at the community level.

\section{Literature Review on Quantification of Resilience}

Identification of an appropriate metric for resilience is necessary in disaster and emergency management. The adoption of a metric can help improve resilience strategies and aid alternative prioritization for hazard mitigation.

Several methods have been proposed for quantification of resilience (Henry and Ramirez-Marquez 2012). Bruneau et al. (2003) and Bruneau and Reinhorn (2007) established 
a framework to conceptualize, define, and enhance seismic resilience of communities using engineering perspectives. They emphasized that a clear definition and identification of its dimensions are necessary in order to quantify resilience. Bruneau et al. (2003) introduced a conceptualized framework for community resilience without presenting any resilience quantification procedure and implementation. Chang and Shinozuka (2004) proposed a series of quantitative measures for resilience. They refined the conceptualization efforts of Bruneau et al. (2003) and proposed a new approach. The refined approach proposed by Chang and Shinozuka (2004) has two advantages over that of Bruneau and colleagues:

- expression of resilience is compact (that is, addresses multidimensional characteristics); and

- expression of a resilience metric is given in a probabilistic format.

They demonstrated the implementation of the quantitative measure of resilience for the Memphis, Tennessee water system. Cimellaro, Reinhorn, and Bruneau (2006) developed a framework for a resilience equation based on the conditional and total probability theorems. They combined structural and nonstructural loss functions, and fragility and recovery functions to calculate resilience. They implemented this approach for a hospital in the San Fernando Valley, California with outputs from the HAZUS earthquake module and applied the same approach to six hospitals in Memphis, Tennessee to calculate their resilience in an earthquake scenario. Bruneau and Reinhorn (2007) tried to quantify seismic resilience of acute care facilities. They focused on seismic resilience, but their goal was to develop general concepts and formulations for other hazards. They included properties of resilience, resourcefulness and redundancy, as the third and fourth dimensions, respectively. Cimellaro (2008a) improved the resilience equation for seismic events with the addition of six sources of uncertainties. He presented a mathematical representation of two dimensions of resilience that is rapidity and robustness and applied his final approach to a hospital in the San Fernando Valley.

Reed, Kapur, and Christie (2009) proposed a methodology to evaluate resilience of subsystems of network infrastructures by combining fragilities and quality characteristics of the infrastructure with an input-output (IO) model for a natural disaster. Resilience of lifelines was measured using fragilities, which are tools to describe the probability of damage for a given level of hazard. Omer, Nilchiani, and Mostashari (2009) suggested a model to measure resilience of a submarine cable system as a network infrastructure. The ratio of the rate of delivery of the system after a disruption to the rate of delivery before the disruption was defined as a reference for resilience. Any hypothetical disruption of the demand, capacity, and flow of information, natural or manmade, was computed node to node to evaluate resilience of the system.

\section{Proposed Methodological Approach}

In this section, the development of an analytical framework for the quantification of resilience is given. Damage state and building type descriptions, structural loss estimation, damage state probabilities as well as wind speed probability, recovery, and loss of use functions are the main working concepts introduced; a resilience indicator is formulated.

\subsection{Formulation of Resilience}

Our study aimed to develop an approach for quantification of resilience that is applicable to different types of buildings, under hurricane threat. It is difficult to formulate the analytical concept of resilience. According to our knowledge, there was only one approach, in which a group of researchers from the Multidisciplinary Center for Earthquake Engineering Research (MCEER) developed a methodology for the quantification of resilience of buildings against an earthquake disaster (Cimellaro, Reinhorn, and Bruneau 2010). They defined the functionality of a system as a variable ranging from 0 percent to 100 percent, where 0 percent means that no service is available, and 100 percent indicates that there is no degradation in service (Cimellaro, Reinhorn, and Bruneau 2006; Cimellaro 2008b). If a disruption occurs, functionality will suddenly drop to a value below 100 percent. The service is assumed to be fully recovered when functionality resumes at 100 percent after a recovery time. Thus, resilience is expressed as an integral of functionality (Bruneau et al. 2003; Bruneau and Reinhorn 2007). Cimellaro, Reinhorn, and Bruneau (2010) also claimed that it was possible to describe various types of functionality for different disasters. They assumed that the type of disaster has an effect on the description of functionality.

In this article, a methodology for quantification of resilience against a hurricane is presented by adopting functionality, and loss and recovery functions from the previous earthquake research (Cimellaro, Reinhorn, and Bruneau 2010). Such an adoption is reasonable, because both earthquakes and hurricanes have different strength levels causing different levels of loss and damage. They both cause loss and damage with certain probabilities. Recoveries from both disasters will depend on preparedness, mitigation, response, and recovery efforts. The methodology presented in this article can also be modified and extended to make it applicable to other types of disasters, after defining the functionality for that disaster.

The new proposed resilience equation has been adopted for a single hurricane event. The developed formulation is being used to compute resilience for individual residential building types or a community consisting of various building types. Probabilistic numbers for a damaged structure as a function of wind speed, called fragility curves, are incorporated into the formulation. Wind speed probability distribution is used to include the effects of wind, within the range of wind speeds for the considered hurricane category. Four 
recovery functions are defined and assigned to all damage states. Actual and expected recovery times are defined and used for each damage state. The resilience of a general building type for each hurricane category is formulated as:

$$
R=100 \int_{w_{1}}^{w_{2}} \frac{1}{T_{e}(w)}\left[\int_{0}^{T_{e}(w)} Q(t, w) \mathrm{d} t\right] P(w) \mathrm{d} w / \int_{w_{1}}^{w_{2}} P(w) \mathrm{d} w \text { Eq. } 1
$$

and functionality is

$$
Q(t, w)=1-\sum_{j=1}^{N_{d s}} L_{j}(w) f_{\text {rec }}^{(j)}\left[t, T_{a}(w)\right]
$$

where $R$ is resilience of a building (\%), $w$ is wind speed, $w_{1}$ is the minimum value of wind speed for the hurricane category considered, $w_{2}$ is the maximum value of wind speed for the hurricane category considered, $T_{e}$ is expected recovery time in which structural losses are predicted to be eliminated (also known as loss of use), $t$ is time, $Q$ is functionality, $P$ is distribution for probability of having winds with a speed of $w, N_{d s}$ is number of damage states, $L_{j}$ is structural losses for damage state $j, f^{(j)}$ rec is recovery function for damage state $j$, and $T_{a}$ is actual recovery time.

Equation 1 can be written as:

$$
R=100 \int_{w_{1}}^{w_{2}}\left[1-\sum_{j=1}^{N_{d s}} L_{j}(w) F_{j}(w)\right] P(w) \mathrm{d} w / \int_{w_{1}}^{w_{2}} P(w) \mathrm{d} w \quad \text { Eq. } 3
$$

where:

$$
F_{j}(w)=\frac{1}{T_{e}(w)} \int_{0}^{T_{e}(w)} f_{r e c}^{(j)}\left[t, T_{a}(w)\right] \mathrm{d} t
$$

is the integral of the recovery function for damage state $j$.

The following general assumptions were made:

- Only structural losses are taken into consideration.

- Only damages due to hurricane winds are taken into consideration.

- Complex terrain effects are not taken into consideration.
- It is assumed that recovery actions will start immediately after a hurricane event occurs.

- It is assumed that the system of interest will continuously recover without interruption.

- Full recovery is not possible, although recovery can be very close to full recovery.

\subsection{Damage State and Building Type Descriptions}

Damage states are described in Hazard in the U.S., HAZUS (U.S. Department of Homeland Security, Federal Emergency Management Agency 2009a), widely accepted software that has been developed by the Federal Emergency Management Agency (FEMA) (Table 1). Since many local and state governments use HAZUS as a loss estimation tool, descriptions of damage states for residential building types are taken from HAZUS in order to use them in the estimation of the resilience indicator. FEMA evaluates structures for municipalities and provides them with recommendations on how to improve strategic planning in case of natural hazards, namely earthquakes, hurricanes, and flooding. HAZUS brings standards for categorization of structures; it is common to see exact descriptions of structures for different regions in the United States. The selection of structure types and descriptions of damage states will both bring standardization and generalization to the computation of resilience.

HAZUS has five damage state descriptions according to external components and cladding of buildings. The summation in Eq. 2 is taken over four different damage states (minor damage $(j=1)$, moderate damage $(j=2)$, severe damage $(j=3)$, and destruction $(j=4))$. There is also a damage state representing no damage or very minor damage, but it is not included in Eq. 2 because it will have a negligible contribution.

\subsection{Structural Loss Estimation Function}

\begin{tabular}{|c|c|c|c|c|c|c|c|}
\hline Damage State & $\begin{array}{l}\text { Qualitative Damage } \\
\text { Description }\end{array}$ & $\begin{array}{l}\text { Roof Cover } \\
\text { Failure }\end{array}$ & Window Door Failure & Roof Deck & $\begin{array}{l}\text { Missile Impacts } \\
\text { on Wall }\end{array}$ & $\begin{array}{l}\text { Roof Structure } \\
\text { Failure }\end{array}$ & $\begin{array}{c}\text { Wall Structure } \\
\text { ailure }\end{array}$ \\
\hline 0 & $\begin{array}{l}\text { No damage or very } \\
\text { minor damage }\end{array}$ & $\leq 2 \%$ & No & No & No & No & No \\
\hline 1 & Minor damage & $>2 \%$ and $\leq 15 \%$ & $\begin{array}{l}\text { One window, door or } \\
\text { garage door failure }\end{array}$ & No & $<5$ impacts & No & No \\
\hline 2 & Moderate damage & $\begin{array}{l}>15 \% \text { and } \\
\leq 50 \%\end{array}$ & $\begin{array}{c}>1 \text { and } \leq \text { the larger of } \\
20 \% \text { and } 3\end{array}$ & $1-3$ panels & $\begin{array}{l}\text { Typically } 5 \text { to } 10 \\
\text { impacts }\end{array}$ & No & No \\
\hline 3 & Severe damage & $>50 \%$ & $\begin{array}{c}>\text { the larger of } 20 \% \text { and } \\
3 \text { and } \leq 50 \%\end{array}$ & $>3$ and $\leq 25 \%$ & $\begin{array}{l}\text { Typically } 10 \text { to } \\
20 \text { impacts }\end{array}$ & No & No \\
\hline 4 & Destruction & Typically $>50 \%$ & $>50 \%$ & $>25 \%$ & $\begin{array}{l}\text { Typically }>20 \\
\text { impacts }\end{array}$ & Yes & Yes \\
\hline
\end{tabular}

Loss is an important economic element of any disaster event. Loss, due to a disruptive event, can be divided into two

Table 1. Damage states for residential buildings in HAZUS

Source: U.S. Department of Homeland Security, Federal Emergency Management Agency (2009a). 
categories: structural and nonstructural. In this article, only the structural losses for different building types are taken into account. Various structural loss estimation methodologies are available. The approaches to loss estimation are mostly probabilistic (Jain, Davidson, and Rosowsky 2005). The most notable structural loss estimation functions were given by Vickery et al. (2006) for developing a loss estimation methodology that was implemented in HAZUS for hurricanes, and by Cimellaro, Reinhorn, and Bruneau (2010), who expressed losses as a function of intensity of an earthquake and recovery time. A detailed explanation of structural loss represented by different researchers was given by Eren Tokgoz (2012). The direct economic structural loss formulation presented by Cimellaro, Reinhorn, and Bruneau (2010) is modified, improved, and used in this research as follows:

$$
L_{j}(w)=\frac{1}{I_{t}} \sum_{i=1}^{N_{m}} I_{i, j} D_{i, j} P_{i}\left(d s_{j} / w\right)
$$

where:

$$
\begin{gathered}
D_{i, j}=\frac{C_{i, j}}{I_{i, j}} \\
I_{t}=\sum_{i=1}^{N_{m}} I_{i, j}
\end{gathered}
$$

where $I_{t}$ is total replacement cost for all building types, $N_{m}$ is number of different building types, $I_{i, j}$ is replacement cost for building type $i$ in damage state $j, D_{i, j}$ is loss ratio corresponding to the ratio of building repair costs to building replacement costs for building type $i$ in damage state $j, P_{i}\left(d s_{j} / w\right)$ is probability to be in damage state $j$ at a given wind speed for building type $i$, and $C_{i j}$ is the repair cost for building type $i$ in damage state $j$.

It should be noted that the structural loss estimation in Eq. 5 takes into consideration the probabilities of being in different damage states for different building types. Damage state probabilities available as damage state graphs (so-called fragility curves) from HAZUS are used (U.S. Department of Homeland Security, Federal Emergency Management Agency 2009b). The methodology requires the probabilities, $P_{i}\left(d s_{j} / w\right)$, for each building type $i$ to be in damage state $j$. These required probabilities can be obtained from the probabilities provided by HAZUS, $P_{i}\left(d s_{j}\right.$ or higher/w), for each damage state of each building type and incorporated into Eq. 5.

Assumption 1: Fragility curves taken from HAZUS pertain to residential buildings in South Florida; the computed resilience data mostly represents that region.

\subsection{Wind Speed Probability}

Russell $(1968,1971)$ was the first who applied mathematical simulation methods to estimate hurricane wind speed for the Texas Coast (U.S. Department of Homeland Security, Federal Emergency Management Agency 2009a). Other researchers have adapted the same approach (Russell and Schueller 1974; Tryggvason, Surry, and Davenport 1976; Batts, et al. 1980; Georgiou, Davenport, and Vickery 1983; Twisdale and Dunn 1983; Georgiou 1985; Vickery and Twisdale 1995a, 1995b). Estimation of hurricane wind speed is important; results of these estimations can be used for risk estimation purposes (Li and Ellingwood 2006). According to the studies of Batts et al. (1980), Peterka and Shahid (1998), and Vickery, Skerlj, and Twisdale (2000), a Weibull distribution is the most appropriate representation for wind speed probability. A special case of a Weibull distribution for wind speed probability distribution is used:

$$
P(w)=\frac{1}{\alpha} \exp (-w / \alpha)
$$

The wind speed distribution in Eq. 8 can be used in Eq. 1 where the limits of the integrations, $w_{1}$ and $w_{2}$, can be obtained from the Saffir-Simpson scale given in Table 2 for each hurricane category.

Assumption 2: Average wind speed for South Florida is assumed to have a uniform distribution with a mean of $9.2 \mathrm{mph}$, and minimum and maximum values of 7.9 and $10.5 \mathrm{mph}$, respectively.

\subsection{Recovery Function}

Defining recovery is difficult since the recovery process is (very) complex and has various associated dimensions. For instance, recovery of a poor neighborhood from a disaster is usually slower compared to that of a rich neighborhood, as expected. In the literature, there is no suggested representation for recovery from hurricanes. Some recovery models are available for earthquake studies. Miles and Chang (2006) did a comprehensive recovery study for earthquakes and applied their model to the Kobe earthquake. Cimellaro, Reinhorn, and Bruneau (2010) suggested some simplified time dependent recovery functions. In their study, the function selected was based on the response of the affected system/society. They proposed linear, exponential, or trigonometric recovery functions as follows:

- The linear recovery function was used when there was no information about preparedness and available resources as well as societal response.

- The exponential recovery function was found to be suitable when the initial response was fast because of the high level of resources and preparedness, and it slowed down later (Kafali and Grigoriu 2005).

Table 2. Saffir-Simpson hurricane damage potential scale

\begin{tabular}{lcc}
\hline Category & Wind Speed $(\mathbf{m p h})$ & Damage Level \\
\hline 1 & $74-95$ & Minimal \\
2 & $96-110$ & Moderate \\
3 & $111-130$ & Extensive \\
4 & $131-155$ & Extreme \\
5 & $>155$ & Catastrophic \\
\hline
\end{tabular}


- The trigonometric recovery function was considered when the response was initially slow due to the lack of resources and preparedness, and it improved over time (Chang and Shinozuka 2004).

The approach for hurricane recovery representation has been inspired by the earthquake study of Cimellaro, Reinhorn, and Bruneau (2010). The same recovery function can be used for all damage states. However, if wind speed is not too high, there may be only minor or moderate damage, and recovery can be very fast. If wind speed is very high, there may be severe damage or destruction, and recovery can be relatively slow. Assignment of separate recovery functions to different damage states is proposed in this article.

The exponential, normal, linear, and sinusoidal recovery functions used in this research are:

$$
\begin{gathered}
f_{\text {rec }}^{(E)}\left[t, T_{a}(w)\right]=\exp \left[\log (1-\lambda / 100) \frac{t}{T_{a}(w)}\right] \quad \text { Eq. 9.a } \\
f_{\text {rec }}^{(N)}\left[t, T_{a}(w)\right]=\exp \left[\log (1-\lambda / 100) \frac{t^{2}}{T_{a}^{2}(w)}\right] \quad \text { Eq. 9.b } \\
f_{\text {rec }}^{(L)}\left[t, T_{a}(w)\right]=\left\{\begin{array}{cc}
1-\frac{\lambda t}{100 T_{a}(w)}, \quad 0 \leq t \leq \frac{100 T_{a}(w)}{\lambda} \\
0, & t>\frac{100 T_{a}(w)}{\lambda}
\end{array} \quad\right. \text { Eq. 9.c } \\
f_{\text {rec }}^{(S)}\left[t, T_{a}(w)\right]= \\
\left\{\begin{array}{c}
\cos \left[\arccos (1-\lambda / 100) \frac{t}{T_{a}(w)}\right], 0 \leq t \leq \frac{\pi T_{a}(w)}{2 \arccos (1-\lambda / 100)} \\
0, \\
t>\frac{\pi T_{a}(w)}{2 \arccos (1-\lambda / 100)}
\end{array}\right.
\end{gathered}
$$

Since it does not seem to be possible to achieve 100 percent recovery, equations 9.a-9.d are defined such that recovery is assumed to be complete when $\lambda$ percent of the initial loss is recovered at time $T_{a}(w)$. Actual and expected recovery times at a given wind speed, $w$, are denoted by $T_{a}(w)$ and $T_{e}(w)$, respectively.
Three different cases are considered for recovery, namely $T_{a}(w)=T_{e}(w), T_{a}(w)<T_{e}(w)$, and $T_{a}(w)>T_{e}(w)$. For illustration purposes, the functionality of the linear recovery function is shown for these three cases in Figure 1. Resilience is proportional to the gray area depicted in Figure 1. If $T_{a}(w)=$ $T_{e}(w)$, recovery is completed at the expected time. If $T_{a}(w)<$ $T_{e}(w)$, recovery is faster than expected, resulting in a larger gray area and higher resilience. If $T_{a}(w)>T_{e}(w)$, recovery takes longer than the expected time, shrinking the gray area and lowering the resilience.

Assumption 3: Exponential, normal, linear, and sinusoidal recovery functions are assigned to minor damage, moderate damage, severe damage, and destruction, respectively. It is assumed that recovery from a hurricane can be modeled by one of these four representations.

Assumption 4: It is assumed that loss ratios, which are the ratios of repair costs to replacement costs, have uniform distributions with mean values of $0.05,0.2,0.45$, and 0.8 , minimum values of $0,0.1,0.3$, and 0.6 , and maximum values of $0.1,0.3,0.6$, and 1 for minor damage, moderate damage, severe damage, and destruction, respectively.

\subsection{Loss of Use Function}

Accurate estimation of recovery time is critical to quantify resilience. In order to estimate recovery time, the calculation of loss of use approach from the hurricane module of HAZUS for residential buildings has been adopted. Five damage states, namely no damage, slight damage, moderate damage, extensive damage, and complete damage, correspond to damages of $0,2,10,50$, and 100 percent, respectively. In the present hurricane model, losses of use for these five damage states are given as $0,5,120,360$, and 720 days, respectively. A linear interpolation is used in HAZUS to compute expected recovery times for loss ratios different from these five cases.

Expected and actual losses of use, in terms of days, are identified as a function of wind speed in order to help with the quantification of resilience. Based on the expected loss of use pertaining to different damage states in HAZUS, expected loss of use is expressed in this article as:

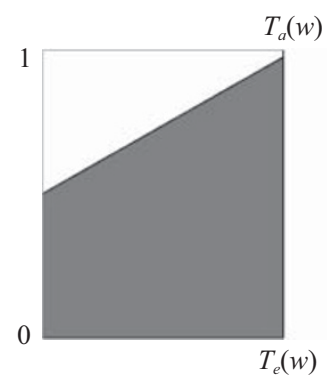

(a)

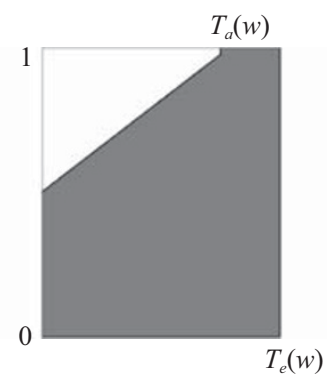

(b)

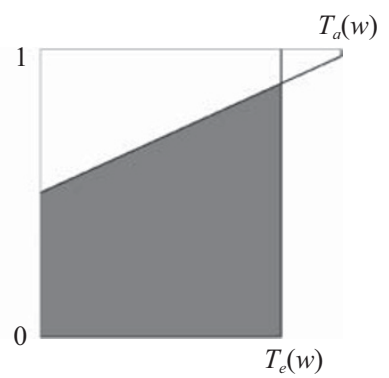

(c)

Figure 1. Functionalities for the linear recovery function. (a) $T_{a}(w)=T_{e}(w)$ with $T_{a}(w)=100$ and $T_{e}(w)=100,(b) T_{a}(w)<T_{e}(w)$ with $T_{a}(w)=80$ and $T_{e}(w)=100$, and $(c) T_{a}(w)>T_{e}(w)$ with $T_{a}(w)=125$ and $T_{e}(w)=100$ 


$$
\begin{aligned}
T_{e}(w)= & T_{e}^{(1)} P_{i}\left(d s_{1} / w\right)+T_{e}^{(2)} P_{i}\left(d s_{2} / w\right) \\
& +T_{e}^{(3)} P_{i}\left(d s_{3} / w\right)+T_{e}^{(4)} P_{i}\left(d s_{4} / w\right)
\end{aligned}
$$

where expected recovery time is weighed with the relevant damage state probability for each damage state, and

$$
T^{(1)}{ }_{e}=5, T^{(2)}{ }_{e}=120, T^{(3)}=360 \text {, and } T^{(1)}=720 \quad \text { Eq. } 11
$$

are expected recovery times for minor damage, moderate damage, severe damage, and destruction, respectively. The actual recovery time is defined as:

$$
\begin{aligned}
T_{a}(w)= & T_{a}^{(1)} P_{i}\left(d s_{1} / w\right)+T_{a}^{(2)} P_{i}\left(d s_{2} / w\right) \\
& +T_{a}^{(3)} P_{i}\left(d s_{3} / w\right)+T_{a}^{(4)} P_{i}\left(d s_{4} / w\right)
\end{aligned}
$$

where $T_{a}^{(1)}, T_{a}^{(2)}, T_{a}^{(3)}$, and $T_{a}^{(4)}$ are the actual recovery times for minor damage, moderate damage, severe damage, and destruction, respectively.

Assumption 5: Actual recovery times are also used for damage states. The actual recovery time can be less than, equal to, or greater than the expected recovery time for each damage state. Actual recovery times for minor damage, moderate damage, severe damage, and destruction are assumed to have Rayleigh distributions with mean values of 5, 120, 360, and 720 , respectively.

\section{Numerical Results}

To demonstrate the proposed methodology, resilience was calculated and compared for Category 1, Category 2, and Category 3 hurricane scenarios. Calculations in this section were done using MATLAB ${ }^{\mathrm{ii}}$ for residential buildings with different roof shapes (for example, hip and gable roofs). Damage state graphs (so called fragility curves) that show the probability of being in a certain damage state versus stormmaximum peak gust speed were found in the Appendices of HAZUS Hurricane Technical Manual for residential buildings (U.S. Department of Homeland Security, Federal Emergency Management Agency 2009b). Selected residential buildings used in the following numerical example have unreinforced masonry walls, $6 \mathrm{~d}$ sheathing, strap roof to wall connection, asphalt shingle roofs, single pane annealed glass windows, tempered glass sliding doors, one-story, and no garages.

\subsection{Monte Carlo Analysis}

A resilience expression in Eq. 1 has multiple parameters with uncertain values. A Monte Carlo analysis was performed to see how resilience varies when these parameters change. Among the parameters, loss ratios and average wind speed are assumed to have uniform distribution given by:

$$
\begin{gathered}
D_{i, 1} \sim U(0,0.1) \\
D_{i, 2} \sim U(0.1,0.3)
\end{gathered}
$$

Eq. 13.a

Eq. 13.b

$$
\begin{gathered}
D_{i, 3} \sim U(0.3,0.6) \\
D_{i, 4} \sim U(0.6,1) \\
\alpha \sim U(7.9,10.5)
\end{gathered}
$$

while actual recovery times for damage states are assumed to have Rayleigh distribution given by:

$$
\begin{array}{lll}
T_{a}^{(1)} \sim \Re\left(T_{e}^{(1)} \sqrt{2 / \pi}\right) & & \text { Eq. 14.a } \\
T_{a}^{(2)} \sim \Re\left(T_{e}^{(2)} \sqrt{2 / \pi}\right) & & \text { Eq. 14.b } \\
T_{a}^{(3)} \sim \Re\left(T_{e}^{(3)} \sqrt{2 / \pi}\right) & & \text { Eq. 14.c } \\
T_{a}^{(4)} \sim \Re\left(T_{e}^{(4)} \sqrt{2 / \pi}\right) & & \text { Eq. 14.d }
\end{array}
$$

A Monte Carlo analysis was performed for a gable roof residential building type by generating a replica of 10,000 random numbers for these parameters. Resilience histograms for the Monte Carlo analysis are presented for that particular building type in the following section.

\subsection{Dashboard Representation for Resilience Acceptability}

In order to evaluate resilience of buildings exposed to hurricanes, green, yellow, and red zones are defined. It is desired to have resilience of a building against a certain category hurricane in the green zone, which shows that the building is sufficiently resilient and only minor damage is likely to be experienced in case of such a hurricane category.

If resilience falls into the yellow zone, it means that the building is more vulnerable while still being quite resilient; moderate damages can most probably happen. If resilience is in the red zone, it raises a red flag, suggesting that resilience has to be improved to avoid a possible severe damage or destruction in case of a hurricane with the category for which resilience is evaluated. The green, yellow and red zones are defined as shown in Figure 2.

The boundaries between red and yellow zones and between yellow and green zones are determined by simplified assumptions. However, boundaries should be determined by decision makers.

In this article, the boundary between red and yellow zones, $R_{r v}$, is defined as:

$$
R_{r y}=\frac{100}{T_{e}^{(2)}}\left[\int_{0}^{T_{e}^{(2)}}\left\{1-D_{i, 2} f_{r e c}^{(L)}\left[t, T_{e}^{(2)}\right]\right\} \mathrm{d} t\right] \quad \text { Eq. } 15
$$

which is obtained by taking $P_{i}\left(d s_{1} / w\right)=0, P_{i}\left(d s_{2} / w\right)=1, P_{i}\left(d s_{3} /\right.$ $w)=0, P_{i}\left(d s_{4} / w\right)=0, T_{e}(w)=T_{e}^{(2)}$, and using linear recovery in Section 3.3. Therefore, $R_{r y}$ corresponds to the resilience of a building that has moderate damage with a probability of 1 and goes through linear recovery within the expected recovery time for moderate damage. The boundary between yellow and green zones, $R_{y g}$, is also defined as: 


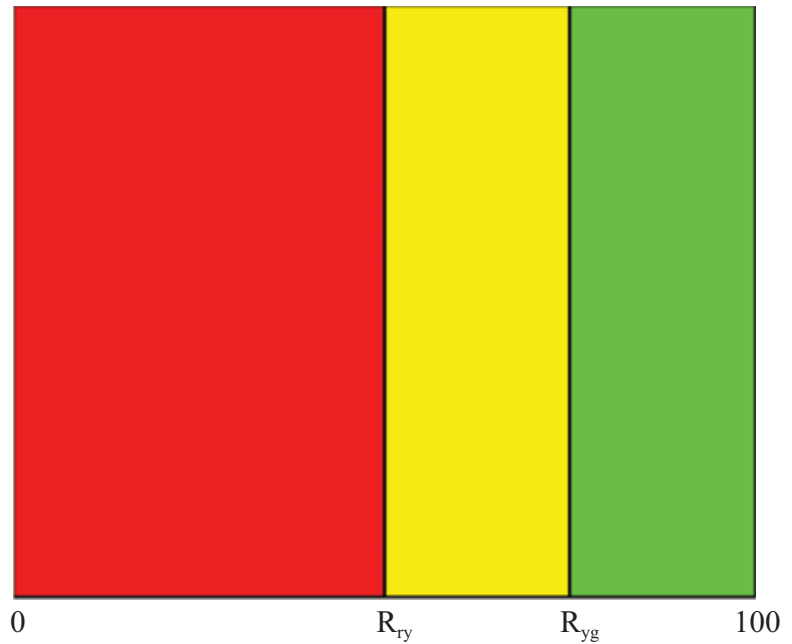

Figure 2. Definition of red, yellow, and green zones for hurricane resilience

$$
R_{y g}=\frac{100}{T_{e}^{(1)}}\left[\int_{0}^{T_{e}^{(1)}}\left\{1-D_{i, 1} f_{\text {rec }}^{(L)}\left[t, T_{e}^{(1)}\right]\right\} \mathrm{d} t\right]
$$

which is obtained by taking $P_{i}\left(d s_{1} / w\right)=1, P_{i}\left(d s_{2} / w\right)=0, P_{i}\left(d s_{3} /\right.$ $w)=0, P_{i}\left(d s_{4} / w\right)=0, T_{e}(w)=T_{e}^{(1)}$, and using linear recovery in Section 3.3. Therefore, $R_{y g}$ corresponds to the resilience of a building that has minor damage with a probability of 1 and goes through linear recovery within the expected recovery time for minor damage.

Assumption 6: In order to be able to interpret the computed resilience data, a dashboard representation consisting of green, yellow, and red zones is defined. The resilience value associated with moderate damage followed by a linear recovery within the expected recovery time is assumed to be the border between the red and yellow zones. The resilience value associated with minor damage followed by a linear recovery within the expected recovery time is assumed to the border between the green and yellow zones.

\subsection{Monte Carlo Analysis Results in a Dashboard Representation}

As explained in Section 4.1, resilience was computed by Eq. 1 with relevance to Category 1, 2, and 3 hurricanes. For numerical calculations, the building selected for computation is a residential building with a gable roof. The resulting histograms for resilience against Category 1, 2, and 3 hurricanes are shown in Figures 3-6, respectively. Each one of the Figures 3-6 visualizes resilience for each recovery function for Category 1, 2, and 3 hurricanes. It should be noted that, for each parameter, 10,000 resilience values were generated using 10,000 random numbers. The range of resilience values was divided into 100 intervals and the number of resilience values that fall into each interval is plotted on a dashboard in Figures 3 and 4 . The vertical axis represents the number of resilience values for each interval on the horizontal axis.

\subsection{Comparison of Monte Carlo Analysis Results for Gable and Hip Roofs for Residential Buildings}

The aim of resilience comparisons is to demonstrate both the applicability of the proposed resilience calculation methodology, and resilient components of the buildings. It is believed that these types of comparisons can be practical for decision makers in the evaluation of mitigation actions for different building types.

During a wind event, roof shape plays an important role in determining the degree of potential damage to a building. Roof shape can be flat, hip, or gable. Only resilience of hip and gable roofs is compared in this section since these two roof shapes are very common in residential structures. Resilience was compared between two Unreinforced Masonry Residential (URM) buildings with the same characteristics, except that one has a gable roof and the other has a hip roof. Resilience data for the 30 replicas of Monte Carlo analysis corresponding to these two building types are compared; results are given in Table 3 .

A National Association of Home Builders (NAHB) Research Center document gives a detailed post-disaster

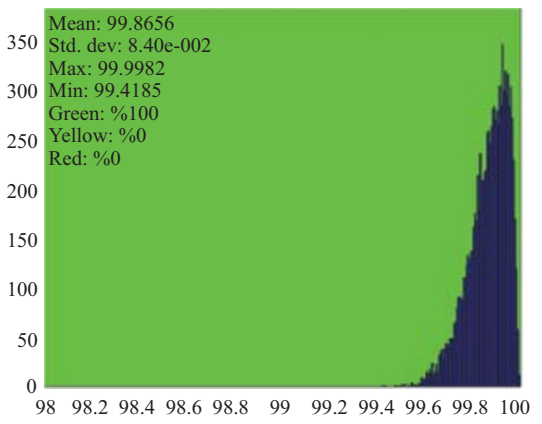

(a)

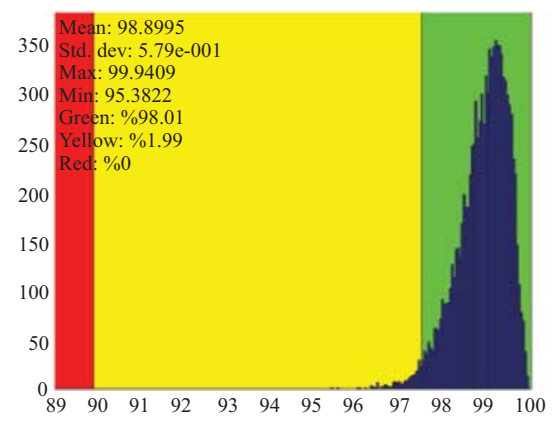

(b)

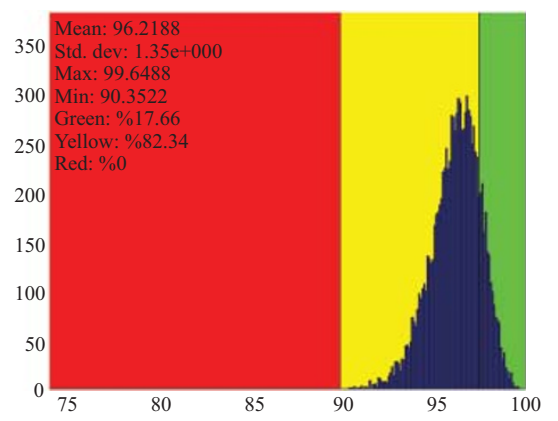

(c)

Figure 3. Histograms of resilience for the exponential recovery function in a Monte Carlo analysis against (a) Category 1 , (b) Category 2, and (c) Category 3 hurricanes 


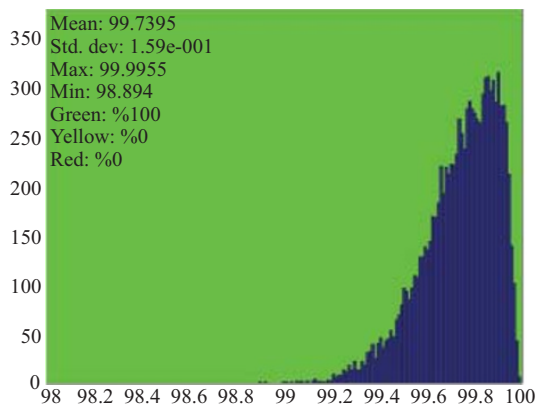

(a)

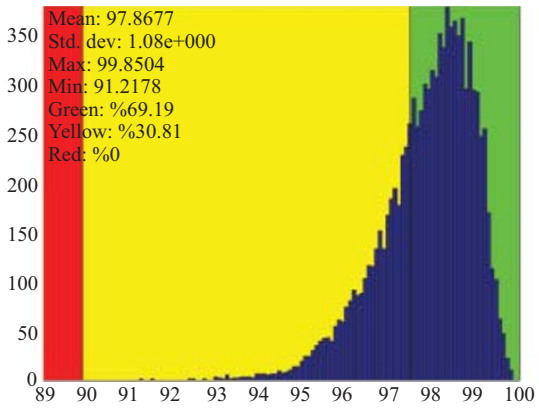

(b)

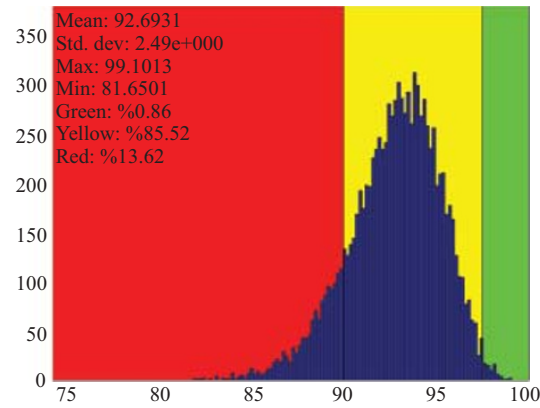

(c)

Figure 4. Histograms of resilience for the normal recovery function in a Monte Carlo analysis against (a) Category 1 , (b) Category 2, and (c) Category 3 hurricanes

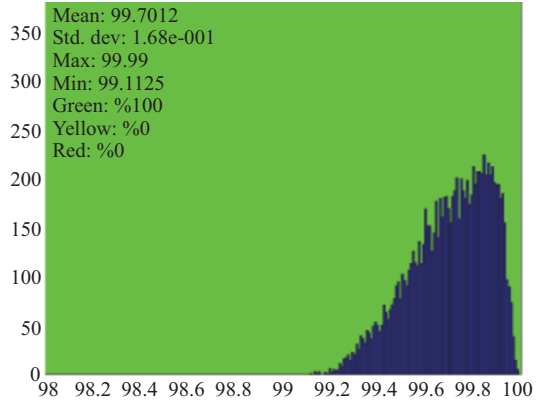

(a)

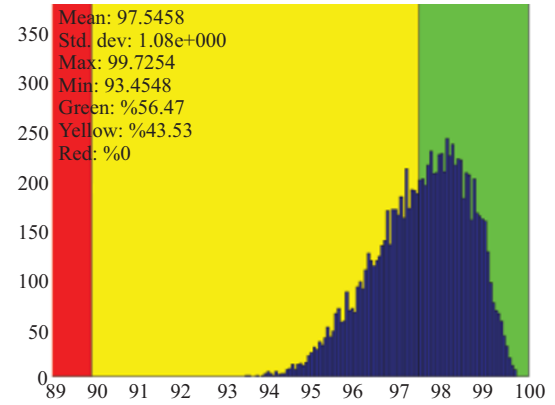

(b)

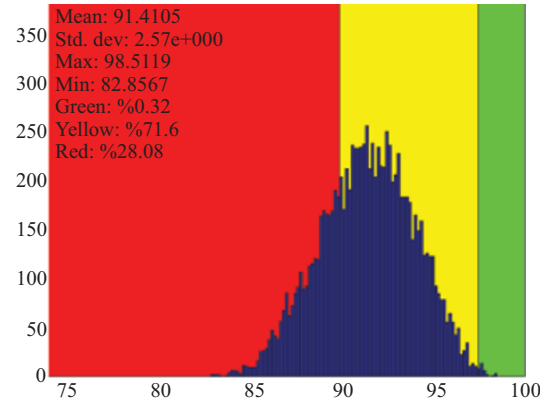

(c)

Figure 5. Histograms of resilience for the linear recovery function in a Monte Carlo analysis against (a) Category 1 , (b) Category 2, and (c) Category 3 hurricanes

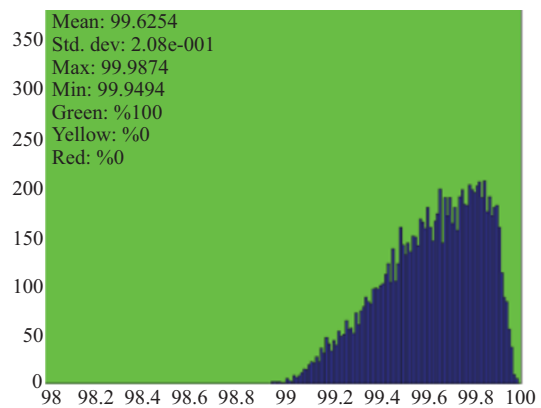

(a)

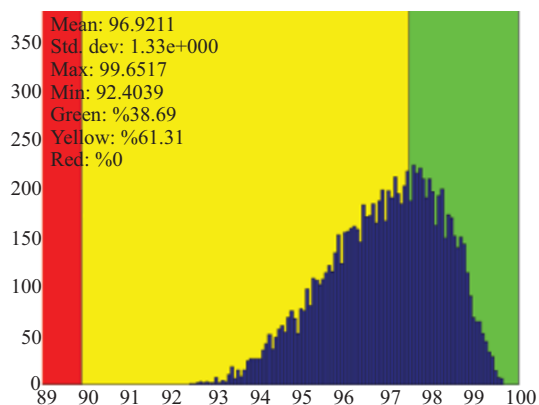

(b)

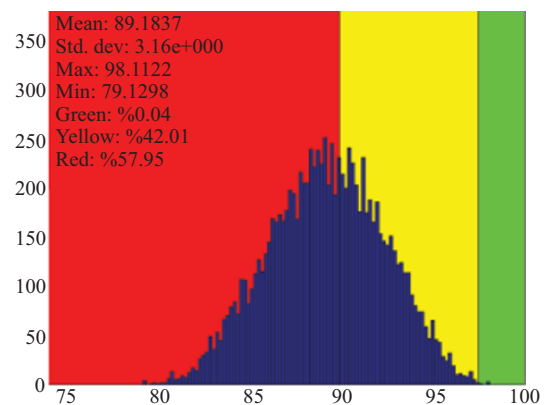

(c)

Figure 6. Histograms of resilience for the sinusoidal recovery function in a Monte Carlo analysis against (a) Category 1 , (b) Category 2, and (c) Category 3 hurricanes

analysis after Hurricane Andrew (NAHB Research Center 1993). This report and the loss estimation methodologies used in HAZUS show that hip roofs are more resistant to wind damage compared to gable roofs. Comparison of the resilience data in Table 3 also shows that hip roofs are more resistant to wind damage. The resilience data in Table 3 are in agreement with the findings of the NAHB document. Mean resilience values are higher for Category 1 and 2 hurricanes for hip roofs compared to gable roofs, but the difference between the mean values of resilience for hip and gable roofs is more significant for Category 3 hurricanes. From the recovery perspective, it is important to notice the difference between the resilience of hip and gable roofs for all recovery types. Exponential recovery is faster than other recovery types.

\section{Conclusions and Future Work}

Attempts to quantify resilience can be found in the literature for different types of disasters. However, quantification of resilience for residential buildings has not been found in the 
Table 3. Comparison of mean values, standard deviations, and percentages in different zones for resilience of building with gable roof and hip roof based on Monte Carlo analysis

\begin{tabular}{|c|c|c|c|c|c|c|c|c|c|c|c|}
\hline \multirow{2}{*}{$\begin{array}{l}\text { Hurricane } \\
\text { Category }\end{array}$} & \multirow{2}{*}{$\begin{array}{l}\text { Recovery } \\
\text { Function }\end{array}$} & \multicolumn{2}{|c|}{ Mean Values } & \multicolumn{2}{|c|}{ Std. Dev. } & \multicolumn{2}{|c|}{ Green (\%) } & \multicolumn{2}{|c|}{ Yellow (\%) } & \multicolumn{2}{|c|}{ Red (\%) } \\
\hline & & Gable Roof & Hip Roof & Gable Roof & Hip Roof & Gable Roof & Hip Roof & Gable Roof & Hip Roof & Gable Roof & Hip Roof \\
\hline \multirow[t]{4}{*}{1} & Exponential & 99.866 & 99.922 & 0.08 & 0.05 & 100.00 & 100.00 & 0.00 & 0.00 & 0.00 & 0.00 \\
\hline & Normal & 99.741 & 99.849 & 0.16 & 0.09 & 100.00 & 100.00 & 0.00 & 0.00 & 0.00 & 0.00 \\
\hline & Linear & 99.703 & 99.828 & 0.17 & 0.10 & 100.00 & 100.00 & 0.00 & 0.00 & 0.00 & 0.00 \\
\hline & Sinusoidal & 99.627 & 99.784 & 0.21 & 0.12 & 100.00 & 100.00 & 0.00 & 0.00 & 0.00 & 0.00 \\
\hline \multirow[t]{4}{*}{2} & Exponential & 98.899 & 99.308 & 0.58 & 0.36 & 97.86 & 99.99 & 2.14 & 0.01 & 0.00 & 0.00 \\
\hline & Normal & 97.867 & 98.661 & 1.07 & 0.68 & 69.39 & 93.69 & 30.61 & 6.31 & 0.00 & 0.00 \\
\hline & Linear & 97.546 & 98.443 & 1.08 & 0.72 & 56.41 & 88.71 & 43.59 & 11.29 & 0.00 & 0.00 \\
\hline & Sinusoidal & 96.921 & 98.043 & 1.32 & 0.89 & 38.14 & 74.09 & 61.86 & 25.91 & 0.00 & 0.00 \\
\hline \multirow[t]{4}{*}{3} & Exponential & 96.212 & 97.577 & 1.34 & 0.92 & 17.17 & 58.61 & 82.83 & 41.39 & 0.01 & 0.00 \\
\hline & Normal & 92.682 & 95.317 & 2.47 & 1.71 & 0.74 & 8.15 & 86.02 & 91.34 & 13.24 & 0.52 \\
\hline & Linear & 91.396 & 94.500 & 2.54 & 1.77 & 0.22 & 3.31 & 71.61 & 96.08 & 28.17 & 0.61 \\
\hline & Sinusoidal & 89.166 & 93.076 & 3.12 & 2.19 & 0.05 & 1.01 & 41.81 & 90.60 & 58.14 & 8.39 \\
\hline
\end{tabular}

literature, especially for a hurricane disaster. Quantification of resilience is important, because it can be used to evaluate and compare mitigation and preparedness strategies. In addition, quantification of resilience can help organize response and recovery actions better. For this purpose, a methodology for quantification of resilience is proposed for residential buildings against a hurricane event. The major objectives, to develop a resilience indicator for buildings against hurricanes, and to compute and visualize resilience of a residential building, were achieved in this research. Formulation of resilience is given in this article in a very general form that is applicable to other structures as well as other hurricane categories. In the proposed methodology, resilience values of residential building types are computed and presented in a dashboard against different hurricane categories. It is believed that dashboard representation of resilience can lead to an ultimate goal of achieving resilience management to support community resilience. In addition, resilience values of two different residential building types (in terms of their roof types) have been compared and results are presented using fragility curves. Resilience calculation employing fragility curves is much more helpful for decision makers to identify better mitigation strategies and preparedness activities to enhance community resilience. Fragility curves are usually used to evaluate damage states of structures based on wind speed, but these curves alone may not help decision makers much. Since it is difficult to find post-hurricane data for different building types, resilience values of buildings, which have different types of roofs, are compared using only NAHB findings. Resilience calculations show that hip roofs are more resilient than gable roofs which are in agreement with the NAHB findings about the resilience of different types of roof against hurricanes.

For future work, resilience of different types of residential structures as well as other types of structures such as essential facilities and commercial buildings can be evaluated with the same methodology. Such a study can be useful to analyze the entire community resilience. It can also provide an opportunity for a comparative resilience analysis among communities. In addition, a user friendly software tool can be developed with a graphical user interface for the proposed methodology. Such a tool can also be very useful for local governments to determine the resilience values for their communities. The obtained resilience values can be used in the prioritization of preparation and mitigation actions in the communities. Formulation of resilience against a hurricane can be extended with the addition of other parameters such as wind direction and debris generation due to a hurricane. Addition of these parameters can yield more precise resilience estimation.

\section{Note}

i HAZUS is a nationally applicable standardized methodology that contains models for estimating potential losses from earthquakes, floods, and hurricanes. The Federal Emergency Management Agency (FEMA) owns HAZUS. For more information, please visit http:// www.fema.gov/hazus.

ii MATLAB is a high-level language and interactive environment for numerical computation, visualization, and programming. For more information, please visit http://www.mathworks.com/products/matlab/.

\section{References}

Batts, M. E., M. R. Cordes, L. R. Russell, J. R. Shaver, and E. Simiu. 1980. Hurricane Wind Speeds in the United States. Report No. BSS-124. Washington, DC: National Bureau of Standards, U.S. Department of Commerce.

Bruneau, M., S. Chang, R. Eguchi, G. Lee, T. O'Rourke, A. Reinhorn, M. Shinozuka, K. Tierney, W. Wallace, and D. von Winterfelt. 2003. A Framework to Quantitatively Assess and Enhance the Seismic Resilience of Communities. EERI Spectra Journal 19 (4): 733-752.

Bruneau, M., and A. Reinhorn. 2007. Exploring the Concept of Seismic Resilience for Acute Care Facilities. EERI Spectra Journal 23 (1): 41-62. 
Carlson, L., G. Bassett, W. Buehring, M. Collins, S. Folga, B. Haffenden, F. Petit, J. Phillips, D. Verner, and R. Whitfield. 2012. Resilience: Theory and Applications. Argonne, IL: Decision and Information Sciences Division, Argonne National Laboratory.

Chang, S. E., and M. Shinozuka. 2004. Measuring Improvements in the Disaster Resilience of Communities. Earthquake Spectra 20 (3): 739-755.

Cimellaro, G. P. 2008a. Improving Seismic Resilience of Structural Systems through Integrated Design of Smart Structures. Ph.D. Dissertation. University of Buffalo SUNY. Available from ProQuest Dissertations and Theses Database. UMI No. 3291587.

Cimellaro, G. P. 2008b. Seismic Resilience of a Regional System of Hospitals. Multidisciplinary Center for Earthquake Engineering Research (MCEER) publication. http://mceer.buffalo.edu/publications/ resaccom/07-SP05/01Cimellaro.pdf.

Cimellaro, G. P., A. M. Reinhorn, and M. Bruneau. 2006. Quantification of Seismic Resilience. Proceedings of the 8th U.S. National Conference on Earthquake Engineering, Paper 1094. San Francisco, California. http://www.eng.buffalo.edu/ bruneau/8NCEE-Cimellaro $\% 20$ Reinhorn\%20Bruneau.pdf.

Cimellaro, G. P., A. M. Reinhorn, and M. Bruneau. 2010. Seismic Resilience of a Hospital System. Structure and Infrastructure Engineering 6 (1-2): 127-144.

Eren Tokgoz, B. 2012. Probabilistic Resilience Quantification and Visualization Building Performance to Hurricane Wind Speeds. Ph.D. Dissertation. Old Dominion University. Available from ProQuest Dissertations and Theses Database. UMI No. 3531603.

Georgiou, P. N. 1985. Design Wind Speeds in Tropical Cyclone-Prone Regions. Ph.D. Thesis. Faculty of Engineering Science, University of Western Ontario, London, Ontario, Canada.

Georgiou, P. N., A. C. Davenport, and B. J. Vickery. 1983. Design Wind Speeds in Regions Dominated by Tropical Cyclones. Journal of Wind Engineering and Industrial Aerodynamics 13 (1-3): 139-152.

Henry, D., and J. E. Ramirez-Marquez. 2012. Generic Metrics and Quantitative Approaches for System Resilience as a Function of Time. Reliability Engineering and System Safety 99 (1): 114-122.

Jain, V. K., R. Davidson, and D. Rosowsky. 2005. Modeling Changes in Hurricane Risk over Time. Natural Hazards Review 6 (2): 88-96.

Kafali, C., and M. Grigoriu. 2005. Rehabilitation Decision Analysis. ICOSSAR'05: Proceedings of the Ninth International Conference on Structural Safety and Reliability. Rome, Italy.

Li, Y., and B. R. Ellingwood. 2006. Hurricane Damage to Residential Construction in the US: Importance of Uncertainty Modeling in Risk Assessment. Engineering Structures 28 (7): 1009-1018.

Miles, S. B., and S. E. Chang. 2006. Modeling Community Recovery from Earthquakes. Earthquake Spectra 22 (2): 439-458.

NAHB (National Association of Home Builders) Research Center. 1993. Assessment of Damage to Single-Family Homes Caused by
Hurricanes Andrew and Iniki, Prepared for the U.S. Department of Housing and Urban Development, Office of Policy Development and Research.

Omer, M., R. Nilchiani, and A. Mostashari. 2009. Measuring the Resilience of the Transoceanic Telecommunication Cable System. IEEE Systems Journal 3 (3): 295-303.

Peterka, J. A., and S. Shahid. 1998. Design Gust Wind Speed in the United States. Journal of Structural Engineering, ASCE 1998. 124 (2): 207-214.

Reed, D. A., K. C. Kapur, and R. D. Christie. 2009. Methodology for Assessing the Resilience of Networked Infrastructure. IEEE Systems Journal 3 (2): 174-180.

Russell, L. R. 1968. Probability Distributions for Texas Gulf Hurricane Effects of Engineering Interest. Ph.D. Dissertation. Stanford University, Stanford, CA.

Russell, L. R. 1971. Probability Distributions for Hurricane Effects. Journal of Waterways, Harbors, and Coastal Engineering Division 97 (1): 139-154.

Russell, L. R., and G. F. Schueller. 1974. Probabilistic Models for Texas Gulf Coast Hurricane Occurrences. Journal Petroleum Technology 26 (3): 279-288.

Tryggvason, B. V., D. Surry, and A. G. Davenport. 1976. Predicting Wind-Induced Response in Hurricane Zones. Journal of Structural Division 102 (12): 2333-2350.

Twisdale, L. A., and W. L. Dunn. 1983. Extreme Wind Risk Analysis of the Indian Point Nuclear Generation Station. Final Report 44T-2491, Addendum to Report 44T-2171. Research Triangle Institute, Research Triangle Park, NC.

U.S. Department of Homeland Security, Federal Emergency Management Agency. 2009a. Multi-Hazard Loss Estimation Methodology Hurricane Model. HAZUS MR4 Technical Manual. http://www.fema. gov/library/viewRecord.do?id=3729.

U.S. Department of Homeland Security, Federal Emergency Management Agency. 2009b. Multi-Hazard Loss Estimation Methodology Hurricane Model. HAZUS MR4 Technical Manual - Appendices. http://www.fema.gov/library/viewRecord.do?id=3729.

Vickery P. J., P. F. Skerlj, and L. A. Twisdale. 2000. Simulation of Hurricane Risk in the United States Using Empirical Track Modeling Technique. Journal of Structural Engineering 126 (10): 1222-1237.

Vickery, P. J., P. F. Skerlj, J. Lin, Jr. Twisdale, M. A. Young, and F. M. Lavelle. 2006. HAZUS Hurricane Model Methodology II: Damage and Loss Estimation. Natural Hazards Review 7 (2): 94-103.

Vickery, P. J., and L. A. Twisdale. 1995a. Wind-Field and Filling Models for Hurricane Wind Speed Predictions. Journal of Structural Engineering 121 (11): 1700-1709.

Vickery, P. J., and L. A. Twisdale. 1995b. Prediction of Hurricane Wind Speeds in the United States. Journal of Structural Engineering 121 (11): 1691-1699.

Open Access This article is distributed under the terms of the Creative Commons Attribution License which permits any use, distribution, and reproduction in any medium, provided the original author(s) and source are credited. 